\title{
Measurement of material volumes in a cylindrical silo using acoustic wave and resonance frequency analysis
}

\author{
Chukiet Sodsri \\ Department of Electrical Engineering, Faculty of Engineering and Industrial Technology, Silpakorn University, Thailand
}

\begin{tabular}{l}
\hline \hline Article Info \\
\hline Article history: \\
Received Dec 10, 2019 \\
Revised Mar 5, 2020 \\
Accepted Mar 23, 2020 \\
\hline
\end{tabular}

\section{Keywords:}

Acoustical system

Cylindrical silo

Material volume estimation

Resonance frequency

System frequency response

\begin{abstract}
This work presents an approach for measuring material volumes in a closed cylindrical silo by using acoustic waves and resonance frequency analysis of silo's acoustic systems. With an assumption that the acoustical systems were linear and time-invariant, frequency responses of the systems were identified via measurement. A sine sweep was generated, amplified and fed to a loudspeaker inside the silo. Acoustic waves were picked up by a microphone and processed to yield the silo's frequency response. Resonance frequencies and wave mode numbers of standing waves in the frequency range below $900 \mathrm{~Hz}$ were analyzed and used for calculation of air-cavity lengths. With known silo's dimension, the material volume estimations were achieved. Sets of experiments for estimating volumes of sand, cement, water, rice grain, and stone flakes in a closed silo, were done. It was found that the approach could successfully estimate the volumes of sand, cement, and water with a satisfactory accuracy. Percent errors of the estimations were less than $3 \%$ from the actual volumes. However, the approach could not estimate the volume of rice grain and stone flakes, since their sound refractions were neither resulted in standing waves nor acoustical modes in the silo.
\end{abstract}

This is an open access article under the CC BY-SA license.

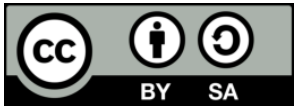

\section{Corresponding Author:}

Chukiet Sodsri,

Department of Electrical Engineering,

Faculty of Engineering \& Industrial Tech., Silpakorn University,

6, Rajamankha Nai Rd., Amphoe Muang, Nakhon Pathom 73000, Thailand.

Email: sodsri_c@su.ac.th

\section{INTRODUCTION}

Silos are used in industries as storage containers of bulk materials and liquids such as cement, carbon black, grain, water, and oil. For containing light and humidity-sensitive materials, the silos are usually closed, oblique, or of solid-wall types. To determine material volumes in such silos, some techniques of volume measurements are requid. Atraditional approachpredicts the silo material volume by making an estimate from a knocking sound. This could yields very inaccurate results since it relies on one's experience and sound characteristics depending not only on air cavity in the silo, but also other physical factors capable of varying with time, such as temperature, humidity, and air density [1]. Measurements of volume levels in the silo utilizing displacement laser and ultrasonic sensors were also found [2-5]. However, due to dusty environment and possible non-flatten material surface in the silo, laser beam could be diffracted into any direction and ultrasonic energy can be easily absorbed. Hence, measurement errors could be high. A continuous level sensor, consisted of a long aluminum tube and guided-wave radar sensor that installed inside the silo has been able to monitor volume level successfully [6-9], but it is only suitable to measure volume of materials with a specific range of dielectric constant. Flow meters can be applied for volume 
measurement of liguid or gas that has smooth flow $[10,11]$ but may not be used for non-flow materials. Ultrasonic flow meter that measures flowrates in pipes can be applied to measure the volumes of liquid or gas remaining in the silo with high accuracy $[12,13]$. However, due to energy absorptivity at high frequency is easily occurred in porous medium, the ultrasonic flow meter may not be able for measuring the bulk volume of granular or non-liquid materials, such as sand, cement, stone flakes, and grain crops.

With theoritical knowledge that standing wave in pipe or air cavity inside a cylindrical tube of rigidwall, natural frequencies and mode numbers are directly related to volume or length of the cavity $[1,14,15]$. By assuming that an acoustical system of the air cavity in the cylindrical silo is linear time-invariant (LTI), it is very possible to perform system identification in frequency domain or measure the system frequency response [16]. Resonance frequencies and wave mode numbers may, then, be extracted from the frequency response and used for estimation of bulk material volumes remaining in the silo.

In this study, we proposed and investigated an approach of usingacoustic waves to estimate material volumes inside a cylindrical silo. With the assumption that the acoustical system of air cavity in a cylindrical silo was LTI, we measured its frequency response by feeding an amplified sine sweep via a loudspeaker to generate an acoustic wave into the silo. The acoustic wave with its reverberation was picked up by a microphone and, then, processed in the frequency domain to obtain the frequency response of the silo and equipment systems. The frequency response of the silo was extracted by dividing the measured frequency response with that of the equipment systems, pre-measured in free-field environment. Resonance frequencies and mode numbers were analyzed from the silo frequency response and then, with prior knowledge of silo dimension, used for calculations of the bulk material volumes in the silo. Sets of experimentations for estimating thevolumes of sand, cement, water, rice grain, and stone flakes in a closed cylindrical silo, were conducted. The results of volume estimations, compared with simulation and actual volumes would justified the approach.

\section{RESEARCH METHOD}

Proposed procedures for measuring material volumes in cylindrical silo by utilizing an acoustic wave were involed with an identification of acoustic system's frequency responses, analysis of harmonic resonance frequencies and their coressponsding wave mode numbers, calculation of air cavity lengths, and estimation of the material volumes in the silo. A conceptual development of acoustical system in the silo, identification of the silo system's frequency responses, and estimation of the material volumes, as well as experimentation using the proposed approach for measuring material volumes in a laboratorysizedcylindrical silo are described in the following sessions.

\subsection{Cylindrical silo and acoustic wave}

Closed cylindrical silos with rigid wall are typically of two types; hopper silo that tapers downward at bottom and flat silo that has flat bottom as shown in Figure 1(a) and 1(b) respectively. With known silos' dimension, diameter and height, if one can measure length of air cavity $(L$ ) inside the silos, one can readily calculate the bulk material volumes ( $V$ ) by using (1) for the hopper silo and (2) for flat silo, where $h$ and $h_{b}$ are heights of cylindrical and tapered parts, $d$ and $d_{b}$ are diameters of the cylindrical part and tapered end of the silo, respectively.

$$
V=\pi\left(\frac{d}{2}\right)^{2}(h-L)+\frac{\pi}{3} h_{b}\left(\left(\frac{d}{2}\right)^{2}+\left(\frac{d}{2}\right)\left(\frac{d_{b}}{2}\right)+\left(\frac{d_{b}}{2}\right)^{2}\right)
$$

or

$$
V=\pi\left(\frac{d}{2}\right)^{2}(h-L)
$$

An acoustic wave in an air cavity in the cylindrical silo of rigid wall, at low frequency and far-field distance, can be approximated as a plane wave as in pipe [1]. When the acoustic wave of low frequencies is incident with bulk volume of materials that does not completely absorb acoustical energy, there will always be a reflected wave in the silo. Let that the wave traveling downward to the bulk materials is in $+x$ direction and the reflected wave traveling upward is in $-x$ direction (see Figure 1(c)). The complex acoustic pressure wave $(\tilde{p})$ and velocity $(\tilde{u})$ as a function of space in one-dimension $(x)$ and time $(t)$ in the silo 
are as in (3) and (4), where $\omega$ is angular frequency, $k$ is wave number, $L$ is distance between acoustic source and the materials, $\rho_{0}$ is density of medium, $c$ is wave speed, $\tilde{A}$ and $\tilde{B}$ are amplitudes of incident and reflected waves traveling in $+x$ and $-x$ directions, respectively [1].

$$
\begin{aligned}
& \tilde{p}(x, t)=\tilde{A} e^{j[\omega t+k(L-x)]}+\tilde{B} e^{j[\omega t-k(L-x)]} \\
& \tilde{u}(x, t)=\frac{\tilde{A}}{\rho_{0} c} e^{j[\omega t+k(L-x)]}-\frac{\tilde{B}}{\rho_{0} c} e^{j[\omega t-k(L-x)]}
\end{aligned}
$$

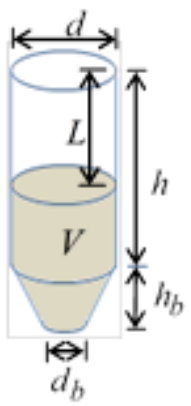

(a)

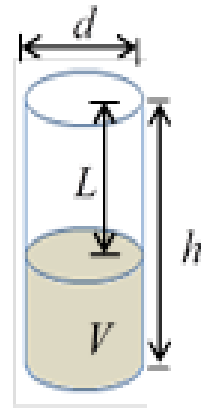

(b)

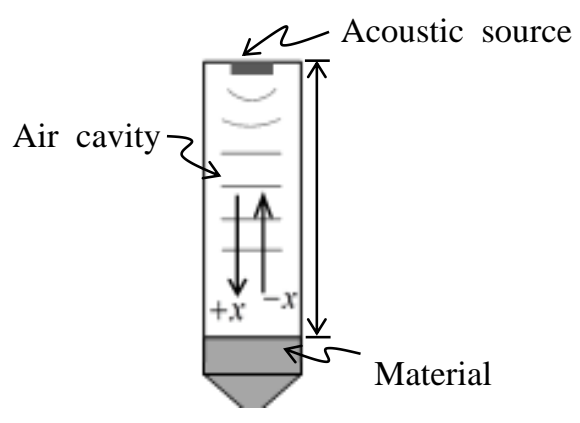

(c)

Figure 1. (a) Hopper silo, (b) Flat bottom silo,

(c) Acoustic source waves in silo travelling downward, incident with materials and reflected upward

Specific acoustic impedance along the height of air cavity is a function of distance $x$, i.e. $\tilde{Z}(x)$ $=\tilde{p}(x) / \tilde{u}(x)$, resulting in (5). Although the bottom end of the cavity in the silo is of materials that its characteristic acoustic impedance may not equal to infinity, it can cause partial reflection and then standing waves due to a mismatch of acoustic impedance and incompletion of acoustic energy absorption, especially for the low frequency wave energy. Modes of the standing waves from the bulk volume material reflection are the same as that from rigid wall reflection. Hence, for simplicity especially when we consider at low frequency, we may use an impedance boundary condition at $x=L$ as if it is infinity. Therefore, for $\tilde{Z}(L)$ $\approx \infty,(5)$ yields $\tilde{B}=\tilde{A}$ and it becomes (6).

$$
\begin{aligned}
& \tilde{Z}(x)=\rho_{o} c \frac{\tilde{A} e^{j k(L-x)}+\tilde{B} e^{-j k(L-x)}}{\tilde{A} e^{j k(L-x)}-\tilde{B} e^{-j k(L-x)}} \\
& \tilde{Z}(x)=-j \rho_{o} c \frac{\cos k(L-x)}{\sin k(L-x)}
\end{aligned}
$$

Since at $x=0$ or upper end of the air cavity is rigid, the impedance boundary condition $\tilde{Z}(0) \approx \infty$ yields a relation of $\sin k L=0$. Acoustic wave numbers $\left(k_{n}\right)$ and natural frequencies of the acoustic standing waves in the silo are then found as in (7) and (8) respectively, where $n$ is mode numbers $(n=1,2,3, \ldots), c$ is sound speed in air which is temperature dependence, approximated out by a formula as in (9), and $T$ is temperature in degrees Celsius [17].

$$
\begin{gathered}
k_{n}=\frac{n \pi}{L} \\
f_{n}=\frac{n c}{2 L}
\end{gathered}
$$




$$
c=331.45 \sqrt{1+T / 273}
$$

An approximation of complex acoustic waves of each mode in low frequency range becomes (10). When sum all modes, the acoustic waves in the cylindrical silo are as in (11). However, if absorption coefficient as a function of frequency $(\alpha(f))$ of materials is known, exact acoustic pressure waves could be obtained. Since the absolute value of acoustic pressure reflection coefficient $(|R|)$ is related to $\alpha(f)$ by the relation of $|R|=\sqrt{1-\alpha(f)}[18,19]$, the exact acoustic pressure in the silo may be further derived.

$$
\begin{aligned}
& \tilde{p}_{n}(x, t)=\tilde{A}_{n} e^{j \omega_{n} t} \cos \left(k_{n}(L-x)\right) \\
& \tilde{p}(x, t)=\sum_{n=1}^{\infty} \tilde{A}_{n} e^{j \omega_{n} t} \cos \left(k_{n}(L-x)\right)
\end{aligned}
$$

\subsection{Silo acoustical system and indentification of its frequency response}

An acoustical system in the cylindrical silo exists, due to an air cavity above the materials. Characteristics of the acoustical system in silo change with variation of the cavity size, inversely proportional to the volume of remaining materials. Some features extracted from system characteristics especially in frequency domain, such as resonance frequencies and wave mode numbers, can be utilized to estimate the cavity size and then compute the remaining material volumes.

Frequency responses of acoustical systems in the silo can be identified via measurement. A system setup for the frequency response measurement is displayed in Figure 2(a) and block diagram in time and frequency domain in Figure 2(b), which is a cascade connection of acoustic wave-generation, silo, and acoustic wave-reception systems. An input to the silo system may be a white noise, pink noise, maximum-length-sequence (MLS), or sine sweep signal [20-25]. In (12) displays the output from the acoustic wave reception system in discrete-time domain, where $y[n]$ and $x[n]$ are measured output and generated input signals, $h_{G}[n], h_{S}[n]$, and $h_{R}[n]$ are impulse responses of acoustic wave-generation, acoustic silo, and wave-reception systems, respectively. By applying Fourier transform, it yields the spectrum equation as (13), where $Y\left(e^{j \omega}\right)$ and $X\left(e^{j \omega}\right)$ are the spectra of the output and input signal, $H_{G}\left(e^{j \omega}\right), H_{S}\left(e^{j \omega}\right)$, and $H_{R}\left(e^{j \omega}\right)$ are frequency responses of the acoustic wave-generation, silo and reception systems, respectively.

$$
\begin{aligned}
& y[n]=x[n] * h_{G}[n] * h_{S}[n] * h_{R}[n] \\
& Y\left(e^{j \omega}\right)=X\left(e^{j \omega}\right) H_{G}\left(e^{j \omega}\right) H_{S}\left(e^{j \omega}\right) H_{R}\left(e^{j \omega}\right)
\end{aligned}
$$

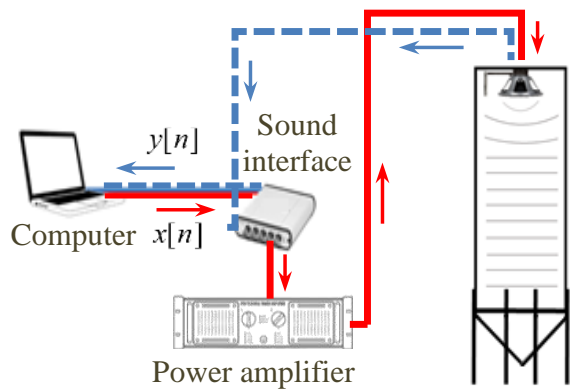

(a)

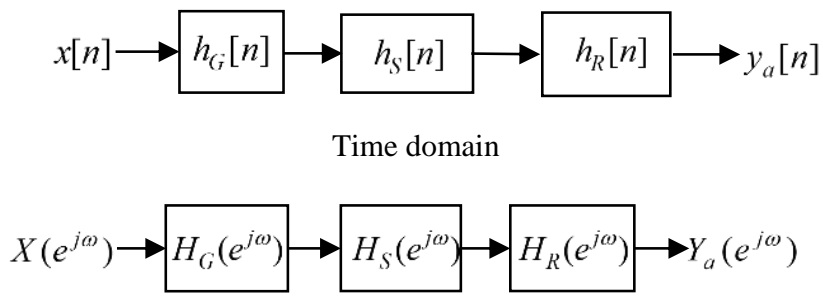

Frequency domain

\section{(b)}

Figure 2. (a) Measurement setup for obtaining frequency response of an acoustical system in silo,

(b) Its block diagram in time and frequency domains

To extract silo frequency response, the same setup of measurement equipments with exact configuration as in the silo, but without the silo (see Figure 3), must be placed in a free-field environment, 
a place with no acoustical system, such as an anechoic chamber. Then, the same input $x[n]$ as in the silo, was used to stimulate the system and the system output ( $\left.y_{a}[n]\right)$ was recorded. In (14) and (15) displayed the output $y_{a}[n]$ and its spectrum. Frequency response of the acoustic silo system could be obtained by dividing the (13) with (15), resulting in (16).

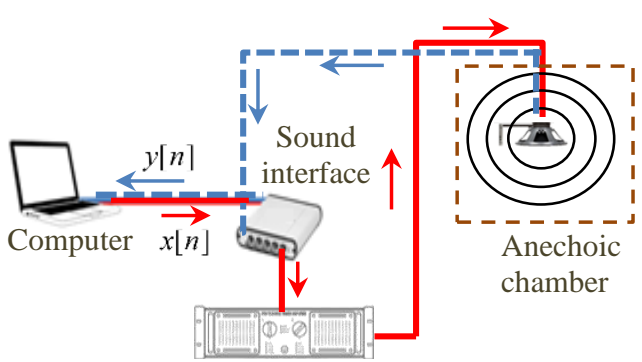

Power amplifier

(a)

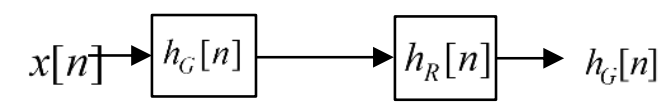

Time domain

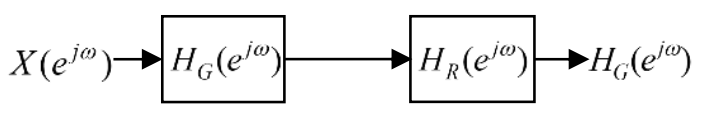

Frequency domain

(b)

Figure 3. (a) Measurement setup in a free-field environment for obtaining frequency response of acoustic wave-generation and reception systems, without silo system,

(b) Its block diagram in time and frequency domains

$$
\begin{aligned}
& y_{a}[n]=x[n] * h_{G}[n] * h_{R}[n] \\
& Y_{a}\left(e^{j \omega}\right)=X\left(e^{j \omega}\right) H_{G}\left(e^{j \omega}\right) H_{R}\left(e^{j \omega}\right) \\
& H_{S}\left(e^{j \omega}\right)=\frac{Y\left(e^{j \omega}\right)}{Y_{a}\left(e^{j \omega}\right)}
\end{aligned}
$$

\subsection{Estimation of material volumes in the cylindrical silo}

Estimation of bulk material volumes in the cylindrical silo can be done based on analyzed resonance frequencies and wave mode numbers from the measured frequency responses of the silo systems. The resonance frequencies $\left(f_{n}\right)$ are the frequencies of harmonic characteristics, where peak magnitudes occur. The corresponding wave mode numbers $(n)$ are sequential integer, multiples of the fundamental frequency. From the obtained resonance frequencies and their corresponding wave mode numbers, the length of air cavity in the silo can be calculated by using (8). With known dimension of the cylindrical silo, i.e. known $h, h_{b}, d, d_{b}$ parameters, the volumes of bulk materials are estimated by using (1) or (2).

\subsection{Experimentation}

A set of experiments for estimating material volumes was conducted in laboratory. A laboratory-sized cylindrical hopper silo made of 3.5 millimeter-thick steel, with dimension of 1.41-meter height, 0.356-meter diameter, and tapered end of 0.267-meter height and 0.052-meter diameter at bottom, was constructed (see Figure 4(a)) to be used in the experiment. Volume estimations of sand, cement, water, rice grain, and stone flakes in the silo were tested. Ten volume levels, from level 1 to 10, volumes of 0.0233 , $0.0342,0.0462,0.0581,0.0701,0.0820,0.0940,0.1059,0.1178$, and 0.1298 cubic meters in the silo were used (see Figure 4(b)).

A measurement system was consisted of a computer, a sound interface, a power amplifier, a loudspeaker, and a microphone. Figure 4(c) depicts the equipment setup in the experimentation and Figure 4(d) displays the loudspeaker and microphone while being pre-measured for their frequency responses in an anechoic room. The computer was used for programming to generate a sine sweep of 10 second length from $40 \mathrm{~Hz}$ to $4000 \mathrm{~Hz}$, fed via the power amplifier to the loudspeaker residing in the silo. Acoustic waves in the silo cavity were picked by microphone and digitized into the computer via the sound interface for signal processing to obtain the frequency responses of the silo acoustical system and the estimations of material volumes in the silo. All codes for controlling equipments and performing the signal processing were done by using LabVIEW programming. 


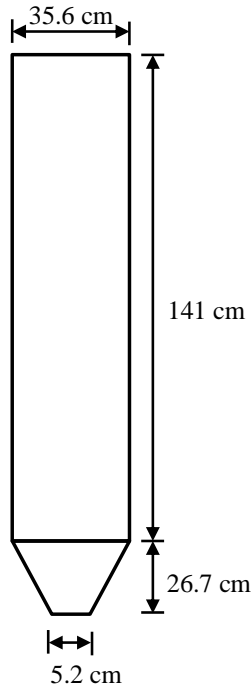

(a)

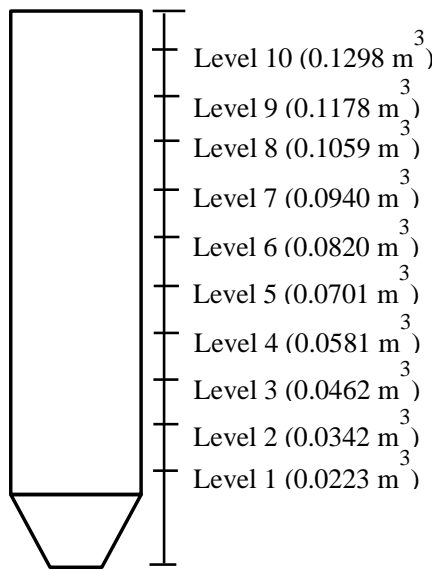

(b)

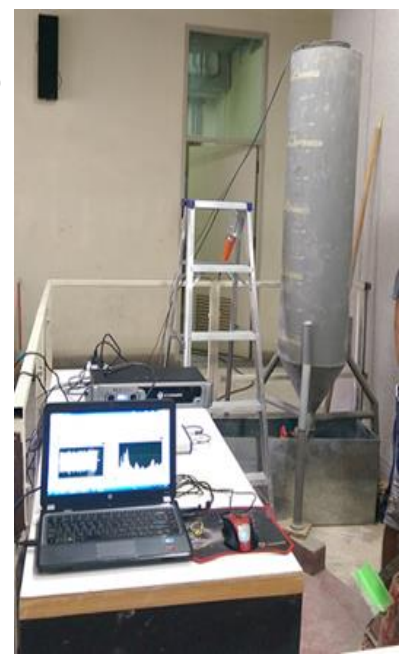

(c)

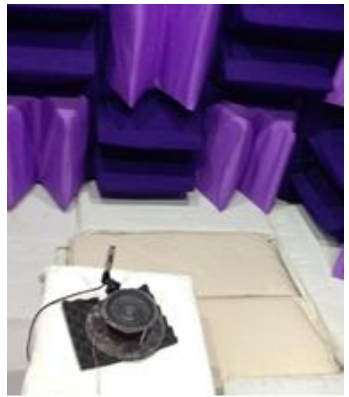

(d)

Figure 4. (a) Dimension of cylindrical silo, (b) Levels of material volumes in the silo to be estimated, (c) Equipment setup for the experiment, (d) Loudspeaker and microphone for installing inside the silo while performing their frequency responses in a hemi-anechoic chamber

\section{RESULTS AND ANALYSIS}

\subsection{Measured frequency responses}

Figure 5 displays a normalized amplitude of measured frequency responses of the cylindrical silo containing sand volume of level-5, compared with that of a silmulated frequency response obtained by taking Fourier transform of the acoustic pressure from (11) for the same volume level, having air cavity length of $0.824 \mathrm{~m}$. As seen, for a low frequency range below $900 \mathrm{~Hz}$, both normalized amplitudes of measured and simulated frequency response are very similar. Their resonannce frequencies at the low frequency, which are frequencies of peak magnitudes, are of harmonic characteristics. These are due to planar reflection causing the standing waves at the low frequency. However, for the high frequency range above $900 \mathrm{~Hz}$, the measured and simulated resonance frequencies are different. At high frequency, acoustical energy of actual acoustic wave traveling in longitudinal direction of the silo may be easily absorbed by the materials. Very few waves were reflected in planar direction and hence harmonic characteristics of standing waves in longitudinal direction become disappeared. In addition at high frequency, standing waves from cylindrical waves traveling in radial and angular directions in which absorbtion by the materials was not occurred, could become dominant as the nonharmonic characteristics are seen in the measured frequency response for the frequency above $900 \mathrm{~Hz}$.

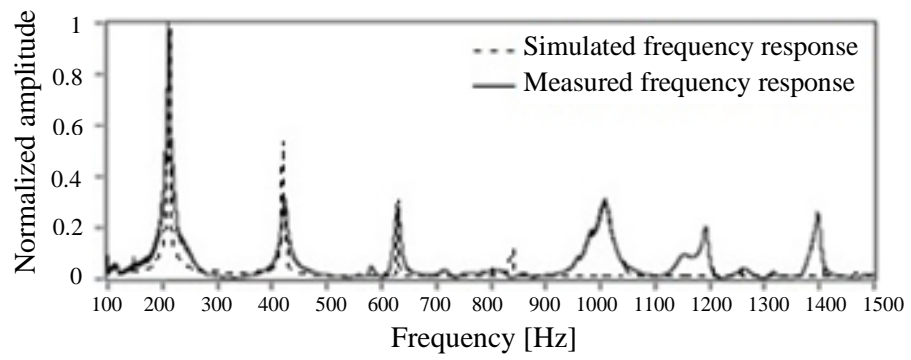

Figure 5. Measured frequency response (line) versus simulated frequency response (dash line) of the acoustic system in the silo containing sand volume of level-5

The harmonic characteristics of the frequency responses in low frequency range were also found for the volume measurements of cement and water in the cylindrical silo. Figure 6 displays examples of 
the measured frequency responses for the silo containing volumes of cement of level 1, 3, 5, 7, and 9 . As seen, the fundamental frequency increases as the cement volume increases. The higher level of cement volumes, the lower number of harmonics and wave modes of the resonance frequencies are.

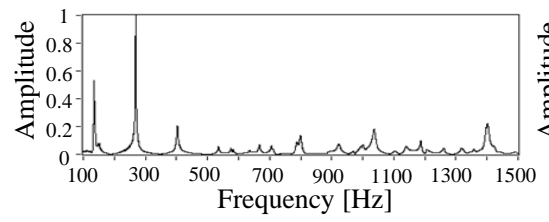

(a)

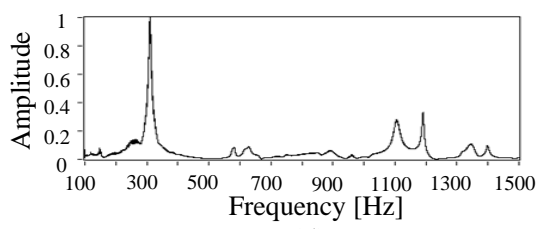

(d)

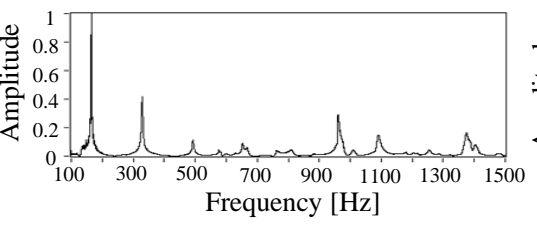

(b)

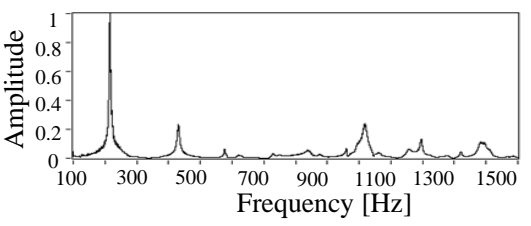

(c)

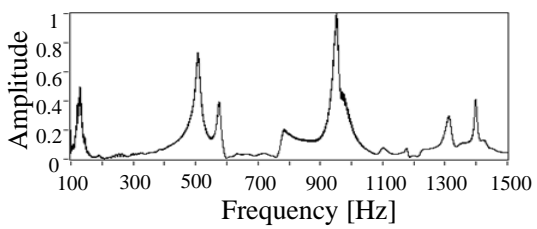

(e)

Figure 6.Measured frequency responses of acoustic systems in the silo containing cement volumes of (a) Level 1, (b) Level 3, (c) Level 5, (d) Level 7, (e) Level 9

For the silo containing every volume level of rice grain and stone flaks, the obtained frequency responses appeared to have non-harmonic characteristics and no coresponding wave mode numbers (see examples of measured frequency responses in Figure 7). The volume estimations of rice grains and stone flakes in the silo could not be done by using the proposed approach. This was due to that when the acoustic plan waves were incident to the rice gains and stone flakes, nonplanar or diffused reflection occurred and hence there were no standing waves taking place in longitudinal direction of the silo and mode number of the resonance frequencies cannot be seen in the silo's frequency response.

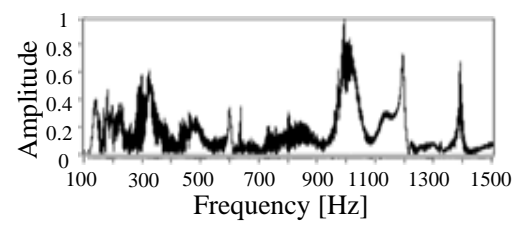

(a)

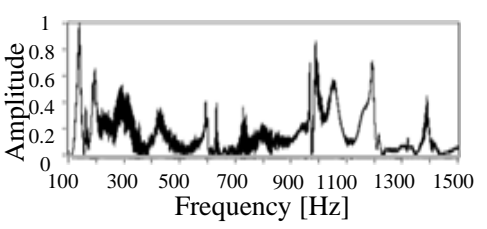

(b)

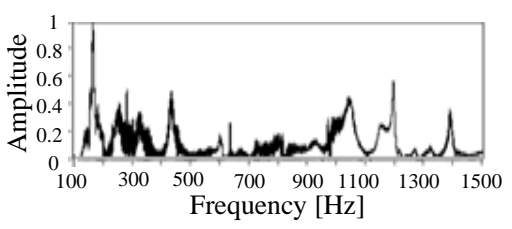

(c)

Figure 7. Measured frequency responses of the silo containing rice gain of, (a) level-1 $\left(0.0533 \mathrm{~m}^{3}\right)$, (b) Level-2 $\left(0.0653 \mathrm{~m}^{3}\right)$ volumes, (c) The silo containing stone flake of level-1 $\left(0.0533 \mathrm{~m}^{3}\right)$ volume

\subsection{Measured material volumes}

Resonance frequencies and wave mode numbers, analyzed from the measured frequency response were used for calculating the length of cylindrical air cavity, based on (8). However, there were several harmonicsand wave mode numbers and they would yield similar values of cavity lengths. An average of these length values was used as the estimated length of the silo air cavity. For example, in the measured frequency response for the silo containg sand volume of level 5 as in figure 5, there are three harmonics with the resonance frequencies of $211.18 \mathrm{~Hz}, 422.09 \mathrm{~Hz}$ and $630.73 \mathrm{~Hz}$, and the corresponding wave mode numbers are 1, 2 and 3. With a sound speed of $347.45 \mathrm{~m} / \mathrm{sec}$ and a temperature during experiment at $27^{\circ} \mathrm{C}$, the calculation from (8) yielded cavity lengths of $82.26 \mathrm{~cm}, 82.32 \mathrm{~cm}$ and $82.63 \mathrm{~cm}$, and their average as the estimated lengthof $82.40 \mathrm{~cm}$. From (1), by using the estimated length of air cavity ( $L$ ) and known dimension of the cylindrical silo, i.e. known $h=1.41 \mathrm{~m}, h_{b}=0.027 \mathrm{~m}, d=0.356 \mathrm{~m}, d_{b}=0.052 \mathrm{~m}$, volume estimates of materials in the silo were computed.

Table 1, 2 and 3 display measured resonance frequencies, calculated cavity lengths, and the volume estimates of sand, cement, and water in the cylindrical silofor 10 tested volume levels. As seen, when the volumes were at low levels, from level 1 to 5, there existed as much as 3 or 4 harmonic resonance 
frequencies. However, when material volumes were at high levels from level 6 to 9 , there existed only one or two harmonic resonance frequencies for use in the estimations. When increasing the tested volume to level 10 , where the actual volume exceeded $80 \%$ of silo's full volume capacity, there was no clear harmonic in the frequency resonance. Hence, the volume estimation at this tested volume level could not be done by using the proposed approach. This was due to that, when material volume levels were high, the length of air cavity became too short and low frequency acoustic waves then could not contribute to a standing wave that had harmonic characteristics. From the estimation results of sand, cement, and water volumes as in Table 1, 2 and 3 , the estimation errors were less than $3 \%$ from the actual volumes. Therefore the volume estimations of finegrain materials and liquid, such as sand, cement and water in the cylindrical silo, were successfully done by utilizing the proposed approach.

Table 1. Measured resonance frequencies of air cavity, calculated heights and estimated bulk volumes of sand in silo

\begin{tabular}{|c|c|c|c|c|c|c|c|c|c|}
\hline \multirow[b]{2}{*}{$\begin{array}{l}\text { Tested } \\
\text { level no. }\end{array}$} & \multicolumn{4}{|c|}{$\begin{array}{l}\text { Measured resonance frequency of air cavity } \\
{[\mathrm{Hz}]}\end{array}$} & \multirow{2}{*}{$\begin{array}{l}\text { Estimated } \\
\text { length of air } \\
\text { cavity }[\mathrm{cm}]\end{array}$} & \multicolumn{4}{|c|}{ Volume of sand $\left[\begin{array}{lll}\mathrm{x} & 10^{-2} \mathrm{~m}^{3}\end{array}\right]$} \\
\hline & $\begin{array}{c}f_{1} \\
(\mathrm{n}=1)\end{array}$ & $\begin{array}{c}f_{2} \\
(\mathrm{n}=2)\end{array}$ & $\begin{array}{c}f_{3} \\
(\mathrm{n}=3)\end{array}$ & $\begin{array}{c}f_{4} \\
(\mathrm{n}=4)\end{array}$ & & $\begin{array}{c}\text { Actual } \\
\text { volume }\end{array}$ & $\begin{array}{l}\text { Estimated } \\
\text { volume }\end{array}$ & $\begin{array}{c}\text { Error } \\
\text { magnitude }\end{array}$ & $\begin{array}{c}\text { Percentage } \\
\text { of error } \\
\text { magnitude }\end{array}$ \\
\hline 10 & - & - & - & - & - & 12.98 & - & - & - \\
\hline 9 & 476.46 & - & - & - & 36.46 & 11.78 & 11.44 & 0.34 & 2.92 \\
\hline 8 & 368.00 & - & - & - & 47.21 & 10.59 & 10.37 & 0.22 & 2.08 \\
\hline 7 & 297.45 & - & - & - & 58.40 & 9.40 & 9.26 & 0.14 & 1.49 \\
\hline 6 & 245.36 & 485.91 & - & - & 71.15 & 8.20 & 7.99 & 0.21 & 2.62 \\
\hline 5 & 211.18 & 422.09 & 630.73 & - & 82.40 & 7.01 & 6.87 & 0.14 & 1.99 \\
\hline 4 & 185.45 & 371.09 & 555.09 & - & 93.73 & 5.81 & 5.74 & 0.07 & 1.25 \\
\hline 3 & 166.00 & 330.36 & 495.09 & - & 105.03 & 4.62 & 4.61 & 0.01 & 0.07 \\
\hline 2 & 147.27 & 294.82 & 441.63 & 587.46 & 118.04 & 3.42 & 3.32 & 0.10 & 2.99 \\
\hline 1 & 134.15 & 267.88 & 402.09 & 535.18 & 129.67 & 2.23 & 2.16 & 0.07 & 2.98 \\
\hline
\end{tabular}

Table 2. Measured resonance frequencies of air cavity, calculated heights and estimated bulk volumes of cement in silo

\begin{tabular}{|c|c|c|c|c|c|c|c|c|c|}
\hline \multirow[b]{2}{*}{$\begin{array}{l}\text { Tested } \\
\text { level no. }\end{array}$} & \multicolumn{4}{|c|}{$\begin{array}{l}\text { Measured resonance frequency of air cavity } \\
\qquad[\mathrm{Hz}]\end{array}$} & \multirow{2}{*}{$\begin{array}{c}\text { Estimated } \\
\text { length of air } \\
\text { cavity }[\mathrm{cm}]\end{array}$} & \multicolumn{4}{|c|}{ Volume of cement $\left[\begin{array}{lll}\mathrm{x} & 10^{-2} \mathrm{~m}^{3}\end{array}\right]$} \\
\hline & $\begin{array}{c}f_{1} \\
(\mathrm{n}=1)\end{array}$ & $\begin{array}{c}f_{2} \\
(\mathrm{n}=2)\end{array}$ & $\begin{array}{c}f_{3} \\
(\mathrm{n}=3)\end{array}$ & $\begin{array}{c}f_{4} \\
(\mathrm{n}=4)\end{array}$ & & $\begin{array}{l}\text { Actual } \\
\text { volume }\end{array}$ & $\begin{array}{l}\text { Estimated } \\
\text { volume }\end{array}$ & $\begin{array}{c}\text { Error } \\
\text { magnitude }\end{array}$ & $\begin{array}{c}\text { Percentage } \\
\text { of error } \\
\text { magnitude }\end{array}$ \\
\hline 10 & - & - & - & - & - & 12.98 & - & - & - \\
\hline 9 & 508.00 & - & - & - & 34.20 & 11.78 & 11.66 & 0.12 & 1.01 \\
\hline 8 & 392.82 & - & - & - & 44.23 & 10.59 & 10.67 & 0.08 & 0.73 \\
\hline 7 & 310.91 & - & - & - & 55.88 & 9.40 & 9.51 & 0.11 & 1.19 \\
\hline 6 & 257.91 & 513.27 & - & - & 67.53 & 8.20 & 8.35 & 0.15 & 1.79 \\
\hline 5 & 215.45 & 430.64 & - & - & 80.66 & 7.01 & 7.04 & 0.03 & 0.49 \\
\hline 4 & 183.82 & 368.18 & 555.09 & - & 94.44 & 5.81 & 5.67 & 0.14 & 2.46 \\
\hline 3 & 165.00 & 329.64 & 493.09 & - & 105.46 & 4.62 & 4.57 & 0.05 & 1.00 \\
\hline 2 & 148.53 & 296.00 & 443.09 & 582.45 & 117.79 & 3.42 & 3.34 & 0.08 & 2.29 \\
\hline 1 & 133.91 & 270.55 & 403.45 & 535.08 & 129.30 & 2.23 & 2.20 & 0.03 & 1.34 \\
\hline
\end{tabular}

Table 3. Measured resonance frequencies of air cavity, calculated heights and estimated bulk volumes of water in silo

\begin{tabular}{|c|c|c|c|c|c|c|c|c|c|}
\hline \multirow[b]{2}{*}{$\begin{array}{l}\text { Tested } \\
\text { level no. }\end{array}$} & \multicolumn{4}{|c|}{$\begin{array}{l}\text { Measured resonance frequency of air cavity } \\
{[\mathrm{Hz}]}\end{array}$} & \multirow{2}{*}{$\begin{array}{l}\text { Estimated } \\
\text { length of air } \\
\text { cavity }[\mathrm{cm}]\end{array}$} & \multicolumn{4}{|c|}{ Volume of water $\left[\mathrm{x} 10^{-2} \mathrm{~m}^{3}\right]$} \\
\hline & $\begin{array}{c}f_{1} \\
(\mathrm{n}=1)\end{array}$ & $\begin{array}{c}f_{2} \\
(\mathrm{n}=2)\end{array}$ & $\begin{array}{c}f_{3} \\
(\mathrm{n}=3)\end{array}$ & $\begin{array}{c}f_{4} \\
(\mathrm{n}=4)\end{array}$ & & $\begin{array}{l}\text { Actual } \\
\text { volume }\end{array}$ & $\begin{array}{l}\text { Estimated } \\
\text { volume }\end{array}$ & $\begin{array}{l}\text { Error } \\
\text { magnitude }\end{array}$ & $\begin{array}{l}\text { Percentage } \\
\text { of error } \\
\text { magnitude }\end{array}$ \\
\hline 10 & - & - & - & - & - & 12.98 & - & - & - \\
\hline 9 & 486.64 & - & - & - & 35.70 & 11.78 & 11.52 & 0.27 & 2.28 \\
\hline 8 & 365.78 & - & - & - & 47.49 & 10.59 & 10.34 & 0.25 & 2.34 \\
\hline 7 & 295.09 & - & - & - & 58.87 & 9.40 & 9.21 & 0.19 & 1.98 \\
\hline 6 & 250.36 & 498.55 & - & - & 69.54 & 8.20 & 8.15 & 0.05 & 0.66 \\
\hline 5 & 216.64 & 430.46 & 642.00 & - & 80.45 & 7.01 & 7.04 & 0.03 & 0.43 \\
\hline 4 & 184.73 & 368.18 & - & - & 94.21 & 5.81 & 5.69 & 0.12 & 2.07 \\
\hline 3 & 166.27 & 331.00 & 495.73 & - & 104.86 & 4.62 & 4.63 & 0.01 & 0.30 \\
\hline 2 & 150.88 & 298.91 & 447.14 & - & 115.98 & 3.42 & 3.52 & 0.10 & 2.97 \\
\hline 1 & 136.27 & 270.55 & 405.00 & 539.82 & 128.33 & 2.23 & 2.30 & 0.07 & 2.99 \\
\hline
\end{tabular}




\section{CONCLUSION}

In this study, a method to estimate bulk material and liquid volumes in a cylindrical silo, by using acoustic wave and resonance frequency analysis, was investigated. An assumption that the silo acoustical system was linear and time-invariant was made, so that the silo frequency response was able to be obtained via measurement. Acoustic waves in the silo were also assumed to be plane in a low frequency range. From experiments, it was found that the measured frequency responses of the silo in the low frequency range below $900 \mathrm{~Hz}$, was in good agreement with that from the simulations. Harmonic resonance frequencies and wave mode numbers were analyzed from the obtained frequency responses and used for a calculation of material volumes. Sets of experiments were conducted to test efficiency of the proposed approach for estimating the volumes of sand, cement, water, rice grain, and stone flakes in the cylindrical silo. The results confirmed that the proposed approach successfully estimate the volumes of sand, cement, and water with high accuracy, as long as, their volumes did not exceed $80 \%$ of silo's full volume capacity. Error percentages of volume estimations were less than $3 \%$ from actual volumes. However, the proposed approach could not be applied for volume estimation of grainy or coarse materials, such as rice grain and stone flake, due to nonplanar or diffused reflection that has no contribution to a standing wave in longitudinal direction of the cylindrical silo. Future research could be developed to study contribution of a cylindrical acoustic wave to resonance in high frequency range which might result in ability of volume estimation of materials at allvolume levels in the cylindrical silo.

\section{ACKNOWLEDGEMENTS}

This research was financially supported by Silpakorn University Research and Development (SURDI), grant no SURDI 58/01/52. Author would like to thanks groups of undergraduate students, ECS III and IV; N. Prasomsup, T. Panthum, N. Lokniyom, K. Tasawang, M. Chairut, and Y. Dechjinda for facilitating and performing some data collection during experimentation in the study.

\section{REFERENCES}

[1] L. E. Kinsler,et al., "Fundamental of acoustics," fourth edition, Wiley,2009.

[2] O. Sonbul,et al., "Ultrasonic sensor array for remote sensing of profiles of bulk materials," Proccedings 2012 IEEE International Instrumentation and Measurement Technology Conference (I2MTC 2012), pp. 1794-1797, 2012.

[3] R. Taylor and M.Shirvaikar,"Performance analysis of range sensors for a real-time power plant coal level sensing system,"The 42nd Southeastern Symposium on System Theory (SSST), TX, USA,pp. 188-193, 2010.

[4] J. D. Lewis, "Technology Review Level measurement of bulk solids in bins, silos and hoppers,"2004. Available: https://www.monitortech.com/-webseminar/WebSeminar_Dec04.pdf.

[5] "Contiuous level sensor functions accurately in dusty environments,"Powder and Bulk Engineering, 2007.

[6] M. Hisashi, "Storage measuring device of silo for storing powder and particle," Japanese Patent 1983047219A, 1983.

[7] E. Yigit, et al., "CS-based radar measurement of silos level," International Geoscience and Remote Sensing Symposium (IGARSS), Milan, Italy,pp. 3746-3749, 2015.

[8] J. L. Gravel and M. C. Fandrey, "Tank seal for guided wave radar level measurement," United States Patent $7255002,2007$.

[9] J. M. Berry and A. M. Gard, "Guided wave radar level transmitter with automatic velocity compensation," United States Patent 6867729, 2005.

[10] S. I. Abdullahi, et al., "Design, simulation and practical experimentation of miniaturized turbine flow sensor for flow meter assessment," Bulletin of Electrical Engineering and Informatics, vol. 8, no. 3, pp. 777-788, 2019.

[11] Bunyamin, et al., "Challenges in turbine flow metering system: an overview," Journal of Physics:Conference Series, vol.1198, no. 4, pp. 1-11, 2019.

[12] G. Rajita and N. Mandal, "Review on transit time ultrasonic flowmeter," The 2nd International Conference on Control, Instrumentation, Energy \& Communication (CIEC), West Bengal, India, pp. 88-92, 2016.

[13] M. F. A. Shaib, et al., "Development of non-invasive ultrasonic measuring system for monitoring multiphase flow in liguid media within composite pieline," International Journal of Electrical and Computer Engineering, vol. 7, no. 6, pp. 3076-3087, Dec 2017.

[14] L. L. Beranek, “Acoustics,” Acoustical Society of America, 1993.

[15] P. Verboven, "Frequency-domain system identification for modal analysis," Ph.D. Thesis, Vrije Universiteit Brussel, 2002.

[16] N.S. Rothman, "Volume determination using acoustic resonance," John Hopkins APL Technical Digest, vol. 12, no. 2, pp. 176-181, 1991.

[17] D. A. Bohn, "Environmental effects on the speed of sound,"Journal of the Audio Engineering Society, vol. 36, no. 4, pp. 223-231, Apr 1988

[18] D. T. Blackstock, "Fundamentals of Physical Acoustics," First edition, Wiley-Interscience, 2000. 
[19] L. L. Beranek and T. J. Mellow, "Acoustics: Sound Fields, Transducers and Vibration," Second edition, Elsevier, 2019.

[20] S. Muller and P. Massarani, "Transfer-function measurement with sweeps," Journal of the Audio Engineering Society, vol. 49, no. 6, pp. 443-471, 2001.

[21] G. B. Stan,et al., "Comparison of different impulse response measurement technique,"Journal of the Audio Engineering Society, vol. 50, no. 4, pp. 249-262, 2002.

[22] A. Farina, "Simultaneous measurement of impulse response and distortion with a swept-sine technique,"108th AES Convention, Paris, 2000.

[23] A. Farina, "Advancements in impulse response measurements by sine sweeps,"122nd AES Convention, Vienna, Austria, 2007.

[24] C. Antweiler, et al., "Perfect-sweep NLMS for time-variant acoustic system identification," International Conference on Acoustics, Speech and Signal Processing (ICASSP), Kyoto, Japan, pp. 517-520, 2013.

[25] I. Szoke, et al., "Building and evaluation of a real room impulse response dataset," Journal of selected topics in signal processing, vol. 13, no. 4, pp. 863-876.

\section{BIOGRAPHY OF AUTHORS}

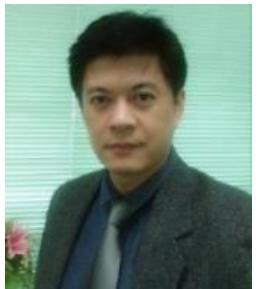

Chukiet Sodsri is currently an assistant professor in department of electrical engineering at Silpakorn universty. He received B.S. in Physics from Silpakorn university, Thailand, M.S. in Electrical Engineering from George Washington university and Ph.D. in Acoustics from Pennsylvania state university, USA. He has been a member of faculty of engineering and industrial technology, Silpakorn university since 1995. His research interest includes signal processing, engineering acoustics, noise control, room and acoustic design, maintenance-based condition monitoring system, and electro-acoustic transducers. 